\title{
Darkrooms, paper tape, punch cards and grease pencils: Doing crystallography at Caltech in the early 1970 s \\ Frank Fronczek ${ }^{1}$ \\ ${ }^{1}$ Dept of Chemistry, Louisiana State Univ \\ ffroncz@lsu.edu
}

\begin{abstract}
My graduate work included structure determination of binuclear Co(III) complexes with bridging peroxo or superoxo ligands. Data collection was on an "automated" quarter-chi circle diffractometer with instructions input and data output on reels of punched paper tape. Reflection location and centering for orientation matrix determination was done manually. So, when crystals were mounted, cell dimensions, crystal orientation and likely space group were already known from Weissenberg and/or precession photographs. Structure solution was by heavy atom (Patterson) methods. Computing was done using the CRYM system on an IBM mainframe computer, with input and output on punched cards. 3D visualization sometimes employed printed Fourier maps, with sections contoured using a grease pencil onto stacked plexiglass sheets. ORTEP was available for publication-quality drawings. The process took a bit longer back then.
\end{abstract}

